\title{
Long Term Electric Load Forecasting for Bonny and Finima Towns using Linear Regression Method
}

\author{
Adebayo Adeniyi D. \\ Electrical/Electronic Engineering Department \\ Federal University, Otuoke \\ Bayelsa State
}

\author{
Emu Chuks \\ Electrical/Electronic Engineering Department \\ University of Port Harcourt \\ Rivers State
}

\begin{abstract}
Electricity production and distribution is very important for developing countries especially Nigeria where power supply is epileptic. In Bonny kingdom, studies about electric energy consumption, distribution and planning is critical in order to manage the currently installed and limited power generating capacity of operating companies and to make important decisions regarding the power systems. This work, carried out long term forecasting of the two electricity suppliers in Bonny Island - Nigeria LNG Ltd (NLNG) and Shell Petroleum Development Company (SPDC). For this research work, recorded load data of last 34 months is collected and used to predict the load of both Finima and Bonny towns for next 10 years. For the load forecast, the linear regression methodology is used for the load growth prediction. This research work will enable the electricity supplier (NLNG, SPDC) and the operating company Bonny Utility Company (BUC) in Bonny Kingdom to plan for proper operation and control of present and future load demand of the power systems.
\end{abstract}

Keywords: Electrical Forescast, Power Systems, Linear Regression Methods, Electricity Supplies and Load Demand for Power System.

\section{INTRODUCTION}

Forecasting has been an existing phenomenon for ages. The ultimate aim of forecasting is to meet future human needs, reduce unanticipated cost and an aid to decision making (Elakrmi F. \& Shikhah N.A., 2013).

Load forecasting involve the projection of electric load demand of certain geographical entity by the use of previous load trends on the said area. Electrical load forecasting has a lot of applications, which include energy pricing and generation, power management, load shedding, contract evaluation and infrastructure development (Isaac A.S. et al, 2014) Bonny Island area has undergone tremendous physical and economic growth in the last two decade as a result of continued industrial development and movement of human skill sets. This growth is expected to continue in the future due to many strategic advantages that Bonny possess. Notably among these advantages are its ready access to deep water, a host community to many oil and gas networks and its prospect for the location for petrochemical and port facilities (Opuenebo B. O., 2004). Currently, Bonny Island host three major companies: the Shell Petroleum Development Company (SPDC) owned Bonny Crude Oil Terminal (BCOT) from where about 30\% of the country's crude is exported; the Mobil Liquefied Petroleum Gas (LPG) plant; and the Nigeria Liquefied Natural Gas (NLNG) plant. These companies are serviced by various contracting firms.

A key growth contributor to Bonny Island is the NLNG plant. The plant has grown from a two train plant in 1999 to a massive six train facility by 2006 . Presently there is an ongoing plan to invest on one more train, to bring the number of trains in the plant to seven. Bonny Island is expected to experience further economic and industrial development in near future. This means more opportunities, growth, pressure on existing infrastructures and huge energy demand.

With the Island located approximately $40 \mathrm{~km}$ from Port Harcourt and surrounded by water, it is virtually cut off from Nigeria's basic infrastructure network - such as road, electricity, water supplies. The common means of reaching out to the island is by water transportation. Power supply to the Bonny community is provided by NLNG and SPDC with a combined supply capacity of $20 \mathrm{MW}$ and is managed by Bonny Utility Company (BUC). Current demand has reached $92 \%$ of this capacity. Electricity tariff for the host communities - Bonny is subsidized; while Finima town is yet to start paying for electricity tariff. Hence the need to review power supply strategy for the host community.

Electricity plays a pivotal role on every activity in Bonny Island. It is the basic source of energy to the industries and currently the only clean source of power for domestic use by the people of Bonny kingdom. For effective use of this scare resources, proper forecasting is necessary. The importance of accurate forecasting ensures the availability of electricity supply and best use of generated capacity.

As noted by Panda S.K (2017), in order to maintain steady supply of electricity to meet demand; early and accurate forecasts are helpful in formulating load management strategies to cope with emerging economic scenarios, which can be merged with the developmental plan of the region.

This paper will look into the effect of electric load growth on existing power generation and distribution systems. According to Phuangpornpitak N. and Prommee W. (2016), load forecasting can be divided into three categories in terms of time scale: short-term forecasts, medium-term forecasts and long term forecasts. 
Short-term forecasts are usually for periods covering one hour to one week. It plays an important role in the day-today operations of a utility such as level and selection of generating capacity to meet actual power demand, economic dispatch and load management.

Medium-term forecasts covers a period of a few weeks to a few months and even up to a few years. This type of forecast is necessary for operational and finance planning fuel procurement, tariff setting, scheduling unit maintenance and revenue assessment for the utilities.

Long-term forecast covers a period of 5 to 25 years. It is used on deciding investment on the system generating capacity and transmission lines expansion plans. Long-term forecasting is a crucial part in the electric power system planning, tariff regulation and energy trading.

\section{I.I. IMPORTANCE}

1. Electricity is vital for the sustenance of every activity in Bonny Island. It is the main source of energy to the industries and power for domestic use in Bonny Island. For effective use of electricity, proper forecasting is necessary. The importance of accurate forecasting ensures the availability of electricity supply and best use of existing generated capacity.

2. The current power demand from Bonny Island community has reached $92 \%$ of the installed
20MW feeder capacity from both NLNG and SPDC. By the completion of anticipated construction of Train-7 at NLNG plant and Bonny-Bodo road, the community power demand shall increase sharply. Thus study will help operating companies and regional Governments to plan for the power requirements of Bonny Island to meet future electricity demands to sustain growth, development and revenue flow.

3. It will also be of immense benefit to other research students as it will serve as reference material for further study on the topic or related topics.

\section{OVERVIEW OF BONY ISLAND}

Bonny Island is a fast growing industrial hub in Niger Delta region of Nigeria. It is situated approximately $40 \mathrm{~km}$ south-east of Port Harcourt in Rivers State, Nigeria (Varlaan P.A.J, 2018).

\section{II.I GEOGRAPHICAL LOCATION}

Bonny Island is located about 4.5 degrees North and south of the inter-tropical convergence zone (ITCZ). It is bordered by the Atlantic Ocean on the southern part.

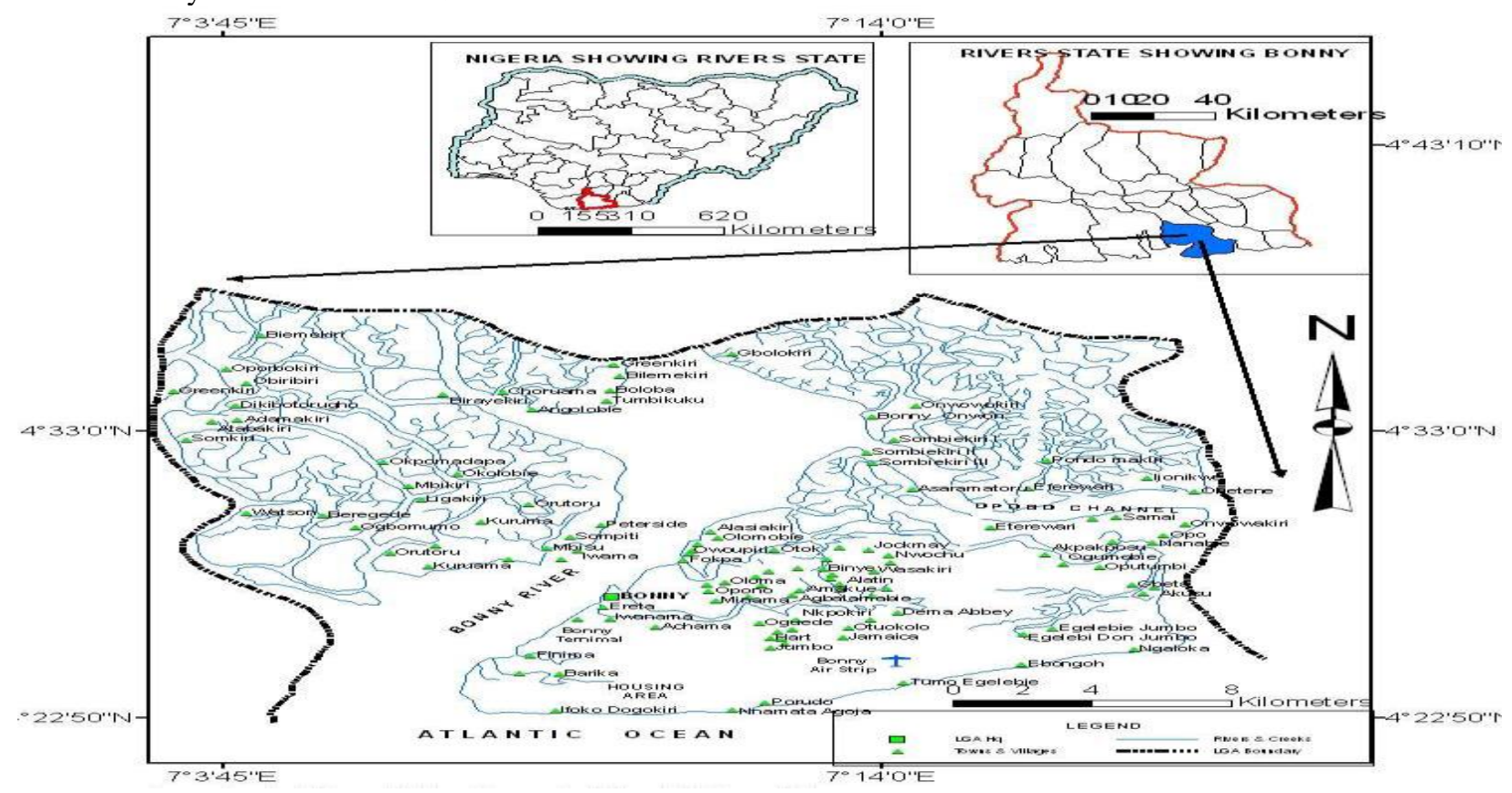

III. OVERVIEW OF LOAD FORECASTING

Load forecasting has been the subject of research for many years both in academia and the power industry. The methods of approach may differ, but the overall intent remains the same: to predict the load or power consumption for an asset or consumer(s) based on some historical data (Patrick D. et al, 2014). Electric load forecasting is a technique used to predict the future power or energy requirement of an entity. Forecasting requires using historical power consumption data to estimate how much power a consumer would need in near future time. Load forecasting is the projection of electrical load that will be required by a certain geographical area using previous electrical load consumption of the said geographical area (Isaac A.S et al, 2014). The data set are analyzed using computational models. Load forecasting has been used by various energy suppliers, institutions to make decisions about power generations, grid expansion plans, tariff pricing among other uses. 


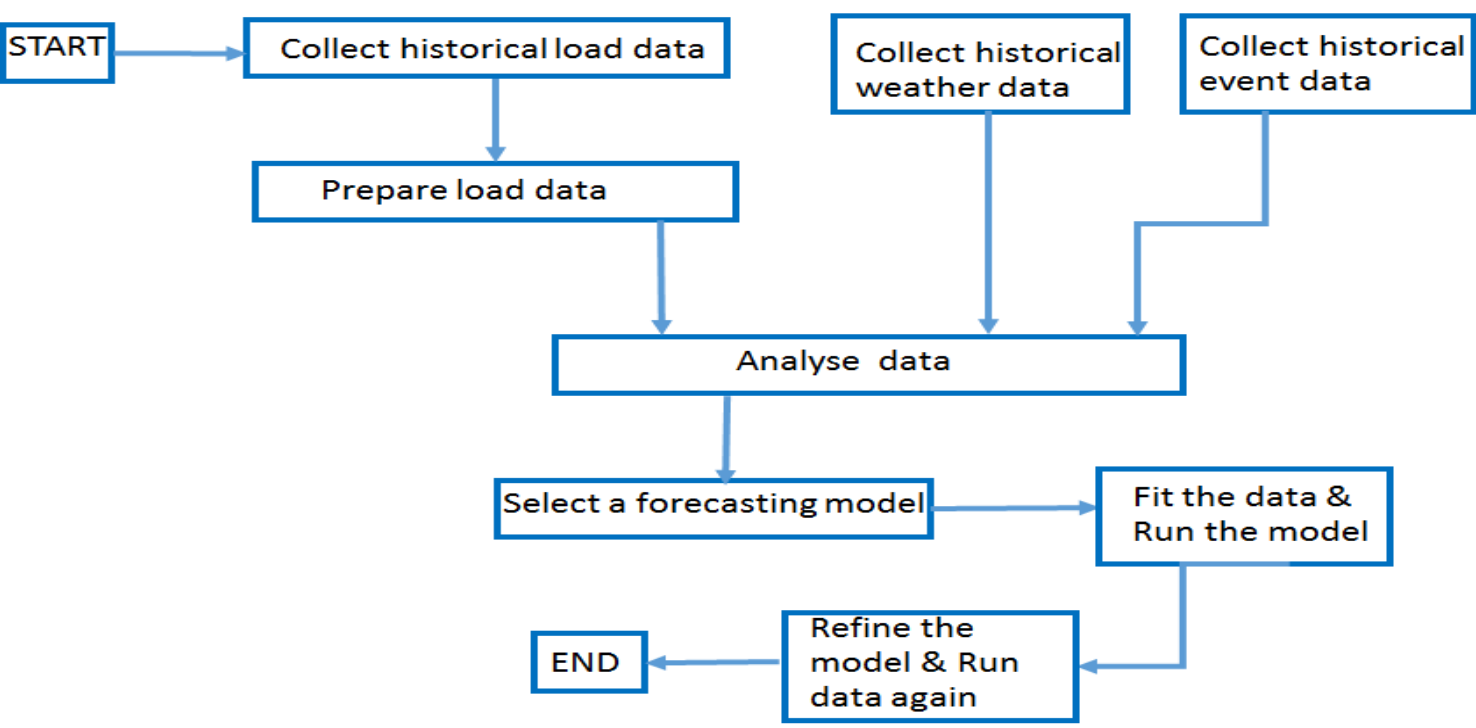

Figure 2.2: Overview of Load Forecasting Model

\section{Factors affecting Long Term Load Forecasting}

There are quite a number of factors that affect long term load forecasting. A few of them are time, weather condition, economic factor, cost of electricity among others (Phuangpornpitak N. \& Prommee W. 2016).

\section{Time factor}

There are specific patterns of load variations with time. Power load also varies with respect to the hour of the day (working, sleeping and leisure hours). It also depend on day of the week. For example, the weekend and holiday load in industries and offices is lesser than week days due to less activity and works. Load also varies with time of the year - raining season versus dry season; winter versus summer periods. By considering the periodic property, load forecast can be predicted effectively.

\section{Economic factor}

Load demand is affected also by economic factors such as industrial development, population growth, electricity cost and per capital income. The higher the industrial development and population growth, the higher the load demand. Economic growth, increase in per capital income leads to better standard of living which stimulate growth in load demand. Cheaper electricity tariff lead to higher load demand as people tend to be extravagant in managing their energy consumption.

\section{Weather Condition}

Weather conditions do affect electric power consumption as well as peak load demand. Seasonal temperature variations affect power consumptions. For instance, during dry season when the average temperature is high, more consumers tend to run their cooling system their by contributing to higher power demand. Other factors such as global warming, rainfall and humidity are directly tied to load demand; hence affects load forecasting.

\section{Review of Load Forecasting Methods}

In general, load forecasting techniques can be classified as either traditional or modern techniques (Singh A.K et al, 2012).

In traditional techniques, time series and multiple regression models are the most common examples of traditional techniques for the short term load forecasting. Historical load data is considered in time series model, while the relations between load and the corresponding variation factors are analyzed in multiple regression models. These statistical techniques are mature and mathematically proven, but most of them are linear in nature.

The relationship between load and the contributing factors affecting its demand is complex and includes non-linear characteristics, making it quite cumbersome to model through statistical techniques without compromising load forecasting precision.

In view of above limitation, modern/intelligent techniques, especially artificial neural networks have been used for load forecasting. These modern techniques are gaining practical importance and have been widely used in electric utilities to do the short term load forecasting.

Electricity demand traditional forecasting techniques can be classified as follows:

- Regression approach

- Multiple regression

- Exponential smoothing

- Iterative reweighted least-squares

- Stochastic time series 


\section{Electricity demand modern forecasting techniques can be} classified as follows:

- Artificial Neural Networks (ANN)

- Rule based expert system

- Fuzzy Logic system

- Support vector machine

- Genetic Algorithm

- Particle Swarm Optimization (PSO) Algorithm

\section{Statistical methods of Load Forecasting}

\section{Regression Approach}

Regression is a very widely used statistical technique in load forecasting. The modelling is performed by considering the relationship of load consumption and other factors that affect is such as weather conditions, economic and time factors.

The mathematical model representing the regression method can be written as:

$$
L(t)=\operatorname{Ln}(t)+\sum_{i=1}^{N} a_{i} x_{i}(t)+\varepsilon(t)
$$

\section{The steps for the regression approach include}

- Select appropriate variables and data, that influence the load

- $\quad$ Assume the functional relationship between inputs and outputs

- Find proper coefficients for this functional relationship

\section{Multiple Regression}

Multiple Regressions is one of the most popular statistical forecasting method. It is often used to forecast load demand affected by a number of factors ranging from weather effects, economic growth, electricity prices, etc. Multiple Regression load forecasting technique uses the principle of least-square estimation (Singh A.K et al, 2012).

The mathematical model representing the multiple regression method can be written as:

$$
Y_{t}=V_{t} a_{t}+\varepsilon_{t}
$$

\section{Exponential Smoothing}

Exponential smoothing is a load forecasting method using data from historic records to predict the future load. The load at time $(\mathrm{t})$ is modelled using the equation

$y_{t}=B_{t}^{T} \times F_{t}+\varepsilon_{t}$

\section{c. Iterative reweighted least-square}

This method uses the autocorrelation function and the partial autocorrelation function of the resulting immediate past load data in identifying a sub-optimal model of the load projection.

$$
Y=X b+\varepsilon
$$

\section{Stochastic Time Series Methods}

Time series methods are based on the assumption that data have an internal structure like trends or autocorrelation (Singh A.K et al, 2012).

The model for time series methods are developed based on the previous load data. Thereafter the future load is predicted based on the developed model (Phuangpornpitak N. and Prommee W., 2016).

\section{Autoregressive (AR) Model}

This model assume a load profile to be a linear combination of previous load data. The AR method can be used to model the load profile by applying the equation

$$
L_{K}=\sum_{i=1}^{N} a_{i K} L_{K-i}+W_{K}
$$

\section{Autoregressive Moving-Average (ARMA) Model}

In the ARMA model the current value of $y(t)$ is expressed linearly in terms of its values at previous periods and in terms of previous values of white noise.

The equation below presents the ARMA model of order $(\mathrm{p}, \mathrm{q})$.

\section{Autoregressive integrated moving-average (ARIMA) model}

If the process under study is dynamic/non-stationary, then transformation of the series to the stationary form has to be done first.

For a series that needs to be differenced d-times and has orders $\mathrm{p}$ and $\mathrm{q}$ for the $\mathrm{AR}$ and MA components, i.e. ARIMA (p; $d ; q)$, the model is written as

$$
f(B) \nabla^{d} y(t)=\phi(B) a(t)
$$

The expression of the operator $\boldsymbol{\nabla}$ is given by

$$
\nabla y(t)=(1-\beta) y(t)
$$




\section{Artificial Intelligence (AI) in Load Forecasting}

According to Elakrmi F. and Shikhah N.A. (2013) majority of the AI-based techniques focus on short term load forecasting (STLF) which is necessary for operational planning. The randomness introduced to loads in STLF is small and the predictions will be more accurate.

For long term load forecasting (LTLF) where there is reasonable degree of uncertainty due to the larger time frame, the AI-based methodologies are less efficient and result in significant forecasting errors when compared to traditional methods. Different AI-based techniques are discussed in the following section.

\section{Artificial Neural Network (ANN)}

Neural network is an artificial intelligent machines that work like the human brain and have building that behaves like biological neurons. Neural networks are interconnected neural computing elements with ability to respond to input stimuli and to learn, adapt to the environment (Olajuyin E. A et al, 2018).

In an ANN, the processing elements are known as neurons. These neurons ate interconnected by information channels called synaptic connections. A representation of a single neuron is as shown in the Figure 2.3.

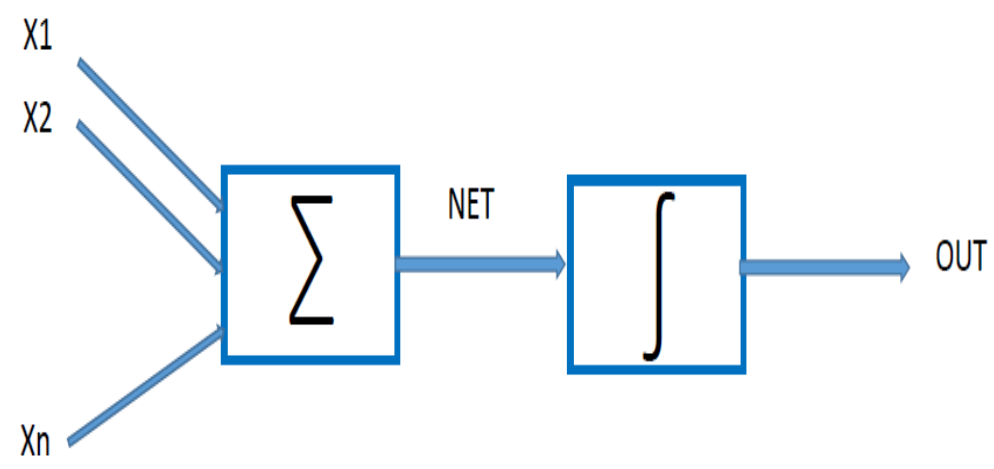

Figure 2.3 An Artificial Neuron

Here, a set of inputs labelled as X1, X2, ...Xn referred to as vector $[\mathrm{X}]$, are applied to the artificial neuron. Each signal is multiplied by an associated weight W1, W2, $\mathrm{W} 3 \ldots \mathrm{Wn}$ referred to as vector [W], before it is applied to the summation block. The summation block adds all of the weighted inputs algebraically producing an output that is termed as 'NET'. This can be represented in the vector notation as
NET $=[\mathrm{X}][\mathrm{W}]$

The NET signal is further processed by an activation function ' $F$ ' to produce the neurons output signal OUT.

The power of neural computation can be obtained by connecting several neurons into networks in a layered neural network format as shown in figure 2.3

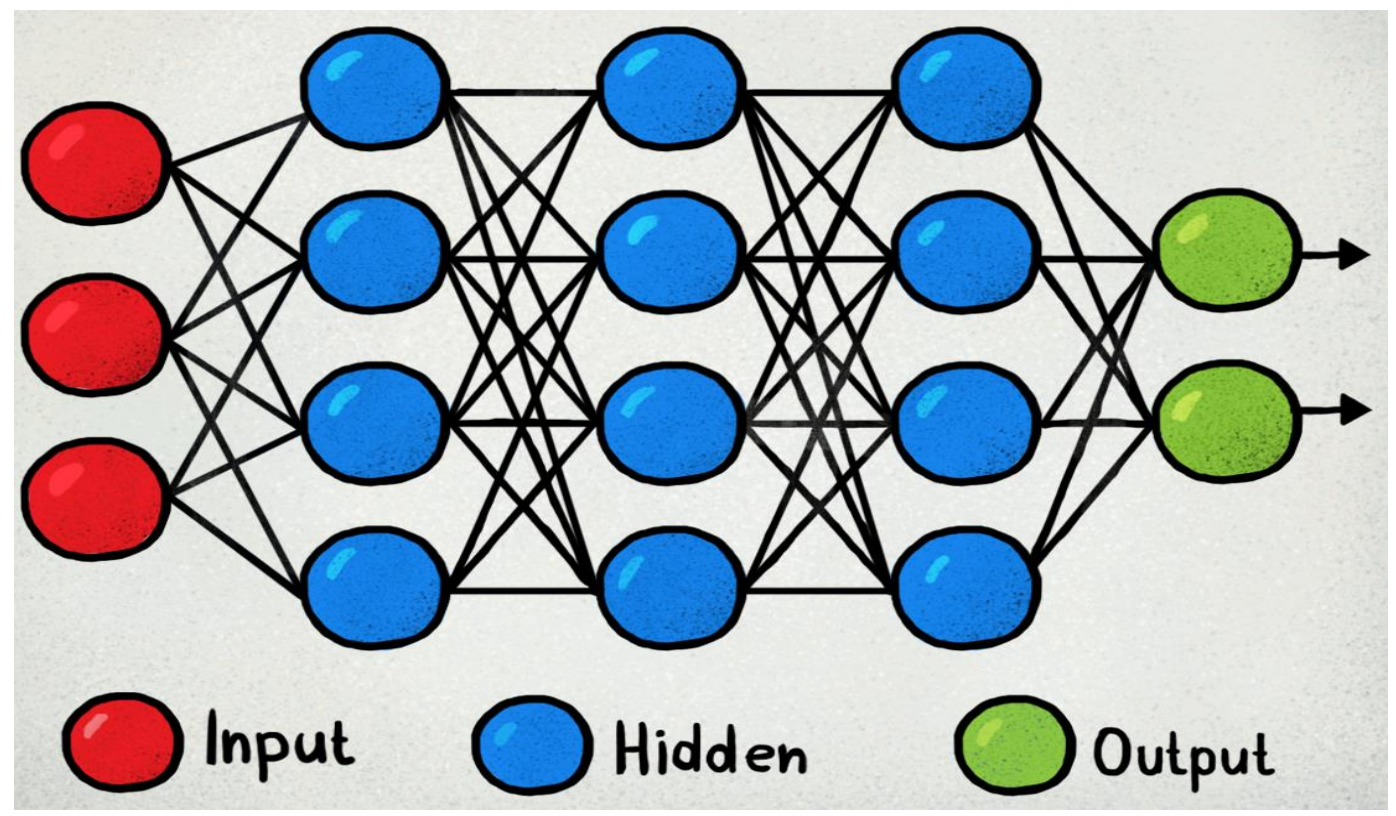

Figure 2.4 ANN Layered Architecture 
In ANN, the neurons are arranged in layers. A neuron receives data or information from the previous layer and transmit data to the next neuron layer ahead of it. The first layer is called the 'Input' layer. The last layer is called the 'Output' layer. The layer(s) between the input and output layers are termed the 'Hidden' layer(s). For load forecasting problem, the input vector (which feeds the input layer) may include different parameters affecting the load such as temperature, humidity, and previous hourly, daily, monthly, and yearly loads etc. The output vector can be the estimated loads at the required time level.

In figure 2.4, a two hidden layered ANN is shown. Each input neuron or node can have multiple inputs but there can only be one output from a node, which can be duplicated and given as input to other neurons. The function of each layer on the network is as defined below:

- The input layer neuron receives external input data

- The input of each hidden layer neuron is summation of the input vector set and the associated weight between the input and the hidden layers.

- The input if the output neuron is obtained by the weighted sum of outputs of the hidden layer neurons.

- The output of a neuron is based on the type of transfer function being considered in the output layer.

The ANNs are robust for modelling non-linear behavior and generalization. It does not require any mathematical equations to describe the functional relationship between input and output variables. ANN learns from experience of the input data provided to it and are able to generalize from previous examples to new ones. They are more robust as compared to conventional techniques.

\section{METHODOLOGY}

The main objective of this paper is to forecast the load demand of Bonny and Finima towns from two different energy suppliers (NLNG and SPDC) for next 10 years. The load growth is expected to be both commercial and residential loads that is expected to increase in near future years following an increase in population and standard of living.

For the study, the load data used were gotten from BUC records of power supplied by both NLNG and SPDC in last 3 -years and using linear regression technique to forecast load demand for next 10-years.

Excel forecasting tool was used for the computations. Using the syntax:

\section{FORECAST $(x$-value, known_y-values, known_x-values $)$}

\section{The Linear Regression Load Forecasting Model}

The linear regression method will be implemented to predict the monthly peak load demand for any particular year.

The formula for the computation is given as

$$
\begin{gathered}
Y=a+b X \\
\sum Y=a+b \sum X \\
\sum X Y=a \sum X+b \sum X^{2}
\end{gathered}
$$

\section{Data Collection}

\section{Input data selection}

In this research work, the monthly peak load data supplied to Bonny Island by NLNG and SPDC for more than 2 years: from January 2017 to September 2019 was collected from Bonny Utility Company (BUC). Monthly temperature data are also collated from 2015 - 2019

The power consumption data obtained from BUC for 2017 -2019 is as shown the figures below:

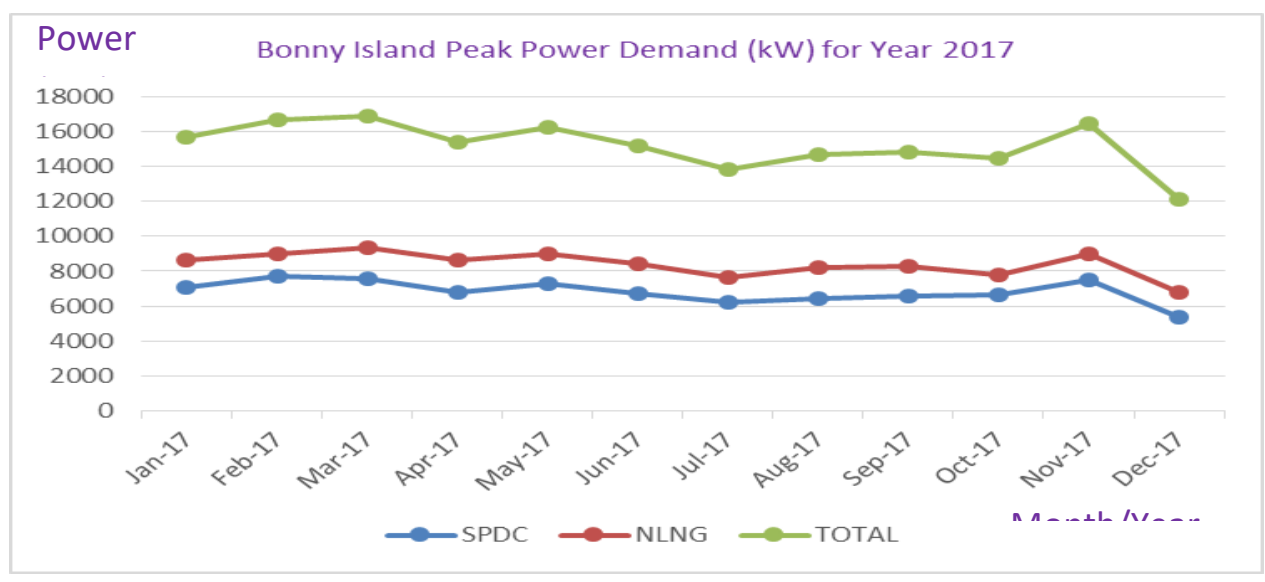

Figure 3.1: Power consumption of Bonny Island for year 2017 


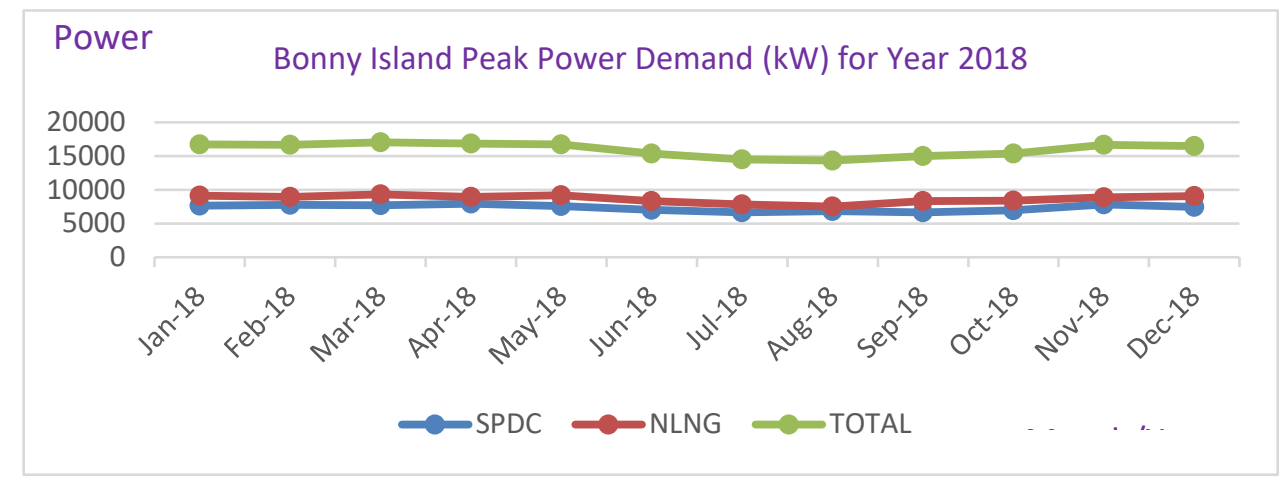

Figure 3.2: Power consumption of Bonny Island for year 2018

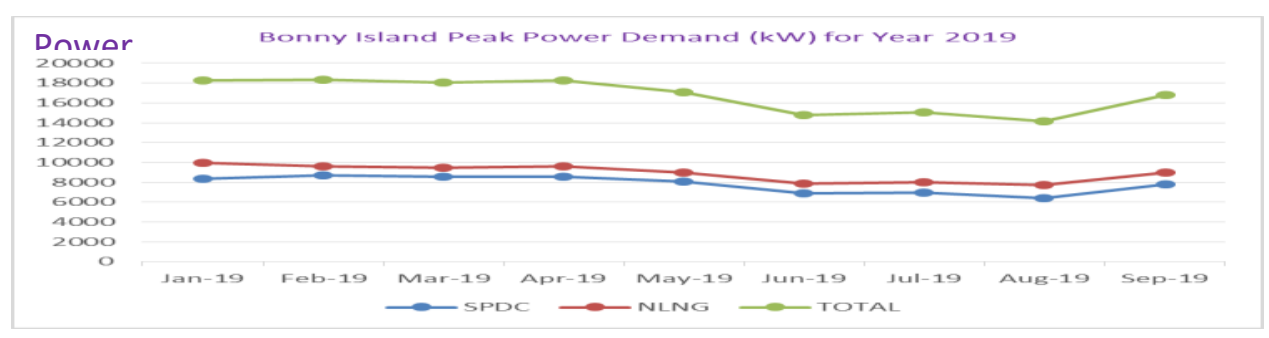

Figure 3.3: Power consumption of Bonny Island for year 2019

Also, the figures below indicate the average air temperature of Bonny Island for a period from 2015 - 2019.

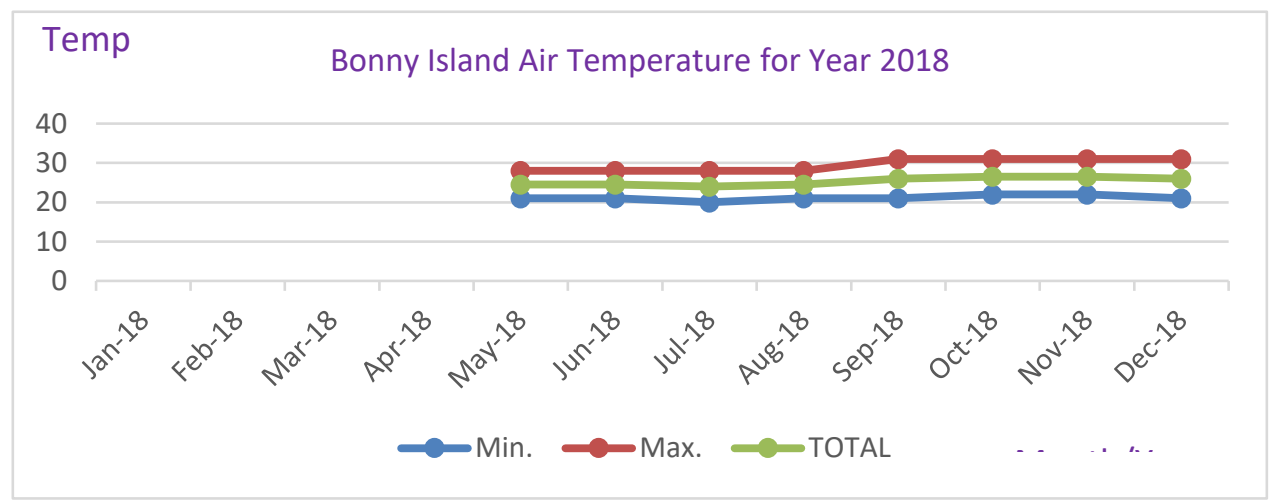

Figure 3.4: Bonny Island Air Temperature for year 2018

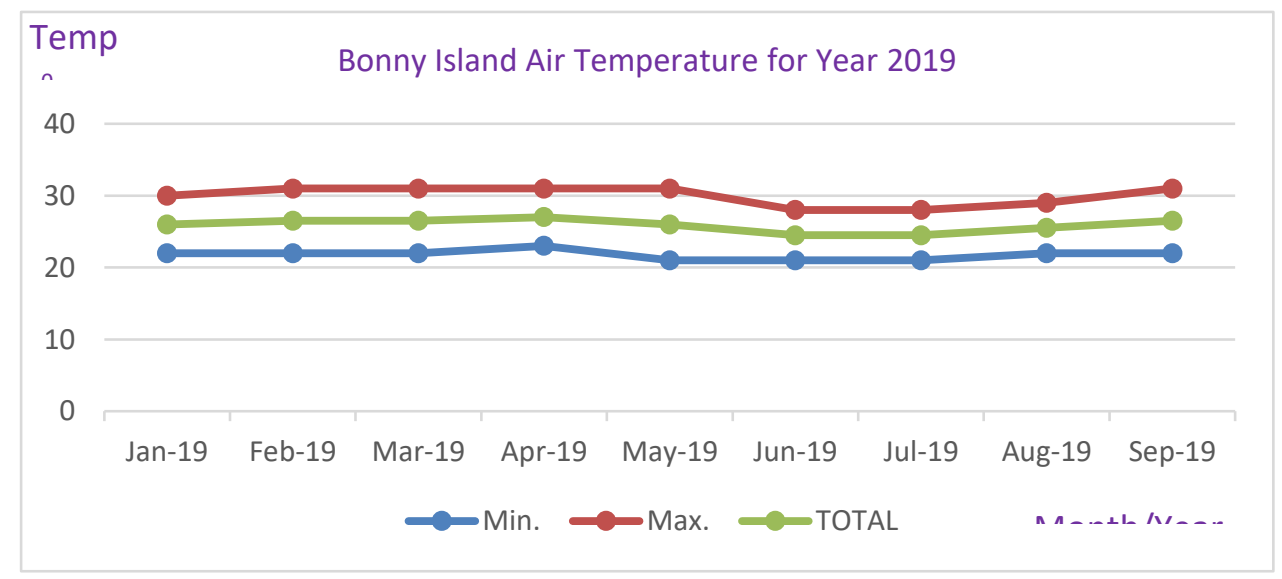

Figure 3.5: Bonny Island Air Temperature for year 2019 


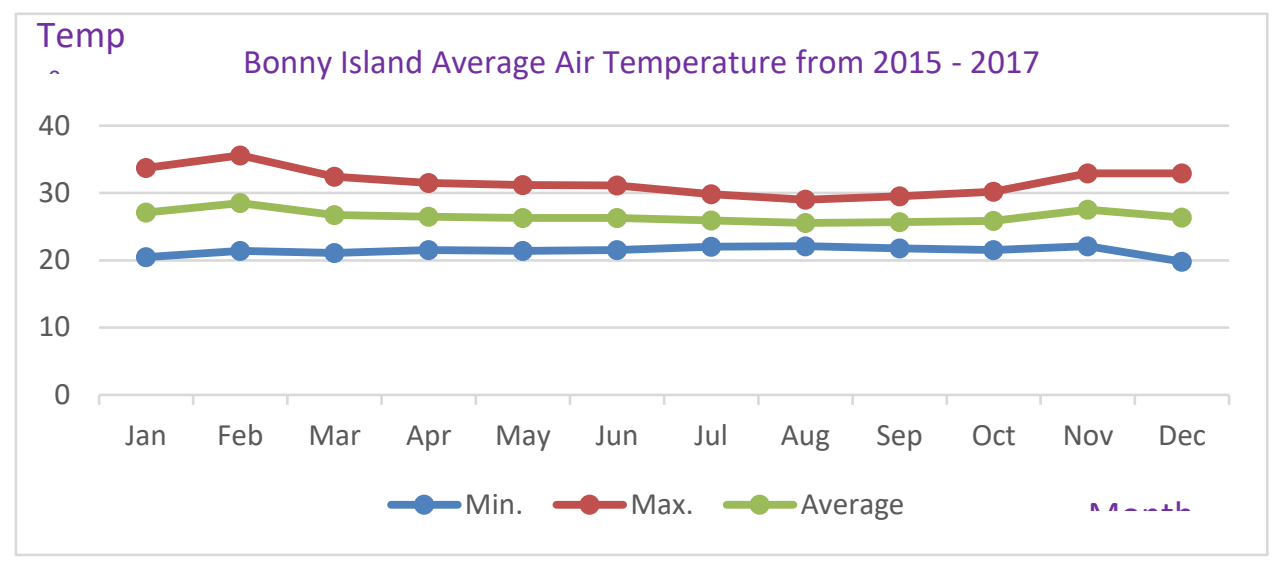

Figure 3.6: Bonny Island Average Air Temperature from 2015 - 2017

Source: Varlaan P.A.J, (2018): Metocean Reference Document for NLNG Train-7 Nigeria

\section{Analysis and discussion of findings}

\section{Discussion of findings}

\section{Measured Load \& temperature data}

The data presented on figures 3.1 to 3.3 show a seasonal pattern on the power demand for the period $2017-2019$. The power demand is fairly steady at an average of $17 \mathrm{MW}$ from November to May with a dip in power demand from June to September to about $15 \mathrm{MW}$. It start to rise steadily again by October. This trend is likely caused by the dry and wet seasons of Bonny as noticed on the temperature profile shown on figures 3.4 to 3.6. Though relatively constant, the temperature of Bonny changes based on the season. Highest temperature of about $33^{\circ} \mathrm{C}$ observed during the end of dry season (February - March) and minimum of $21^{\circ} \mathrm{C}$ during the peak of raining season (July - August).

Inputing the values for the forecasted months and years gives the predicated power demand for next 10-years as shown on figure 4.1 to 4.11 below.

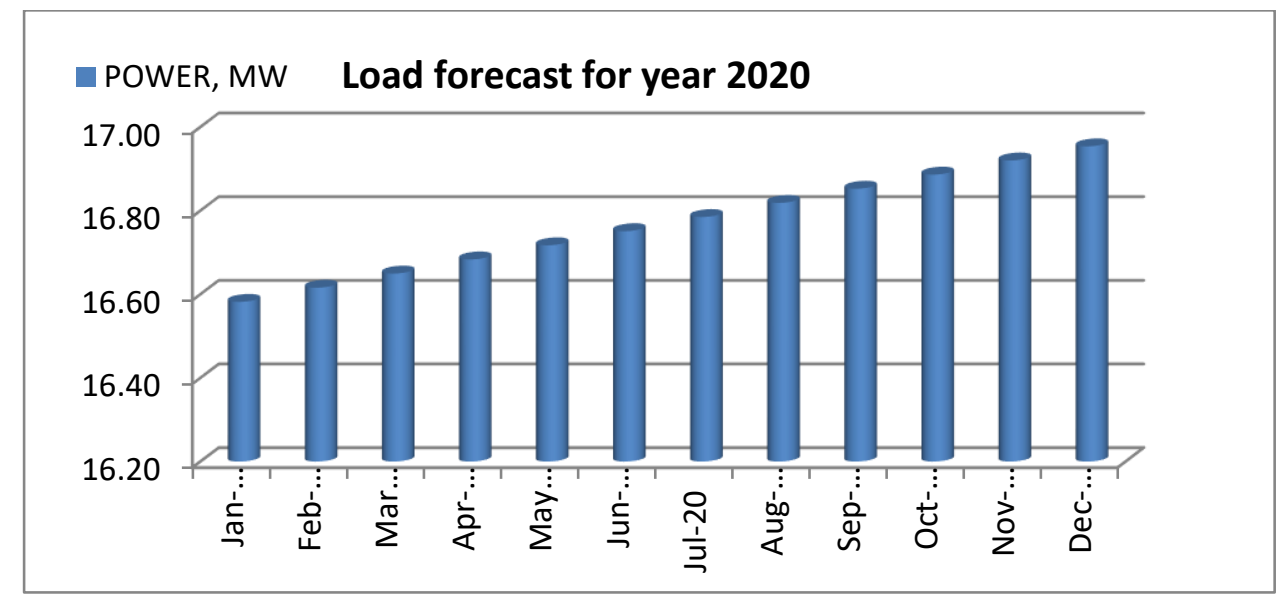

Figure 4.1: Bonny Island year 2020 load forecast 


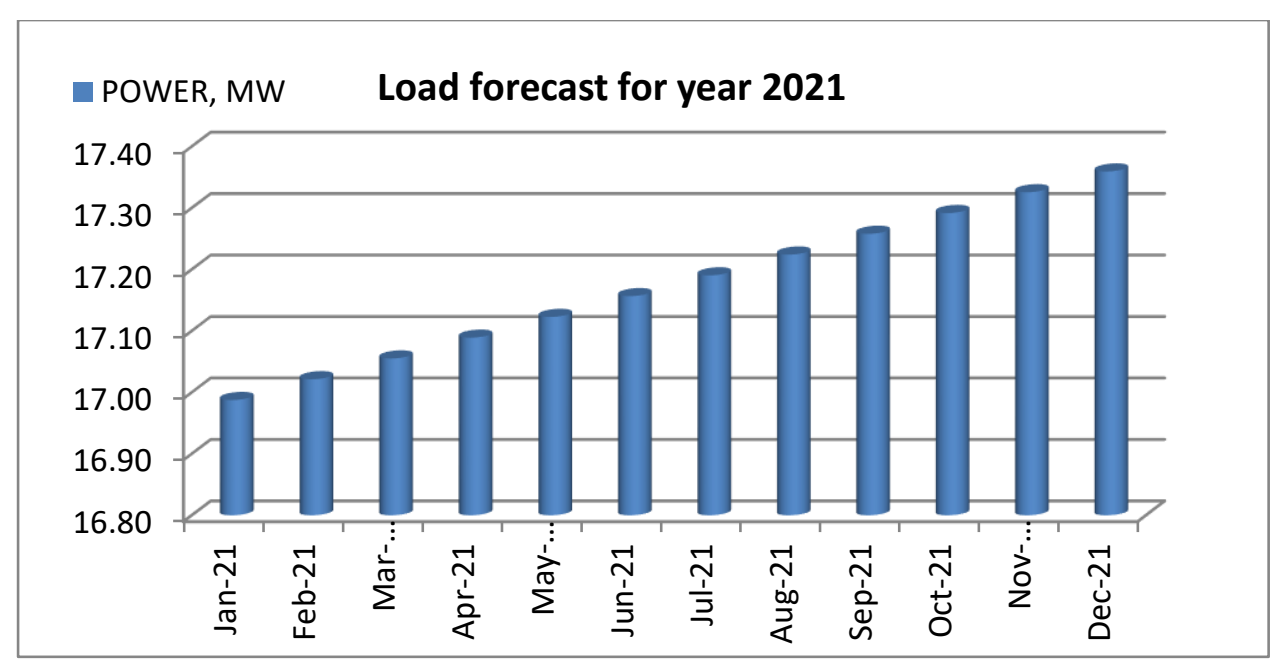

Figure 4.2: Bonny Island year 2021 load forecast

a POWER, MW L Load forecast for year 2022

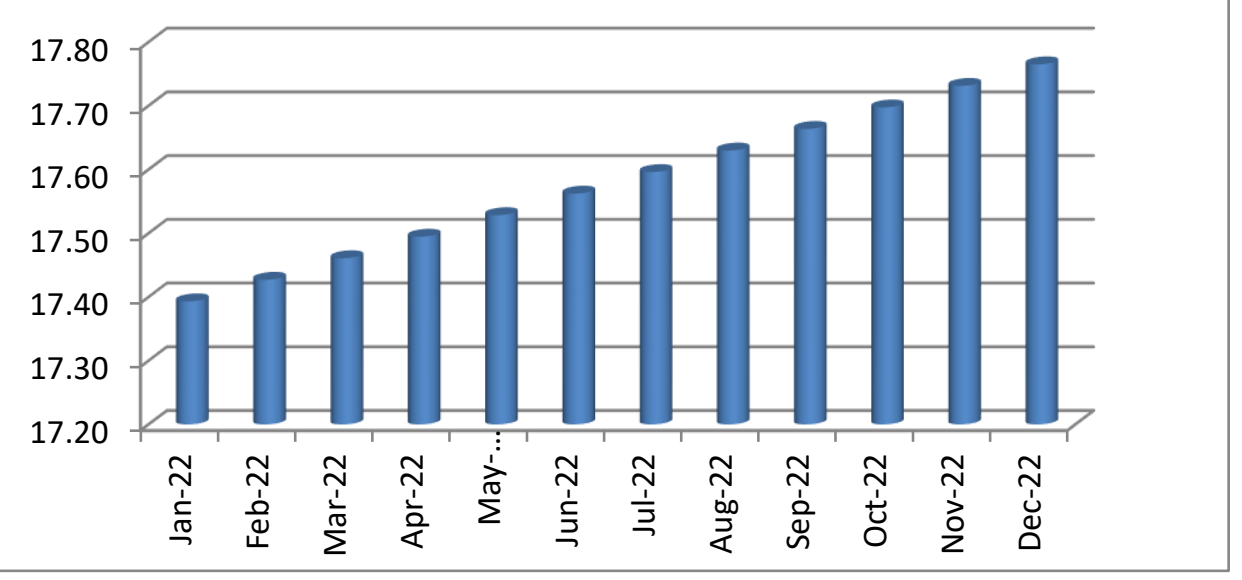

Figure 4.3: Bonny Island year 2022 load forecast

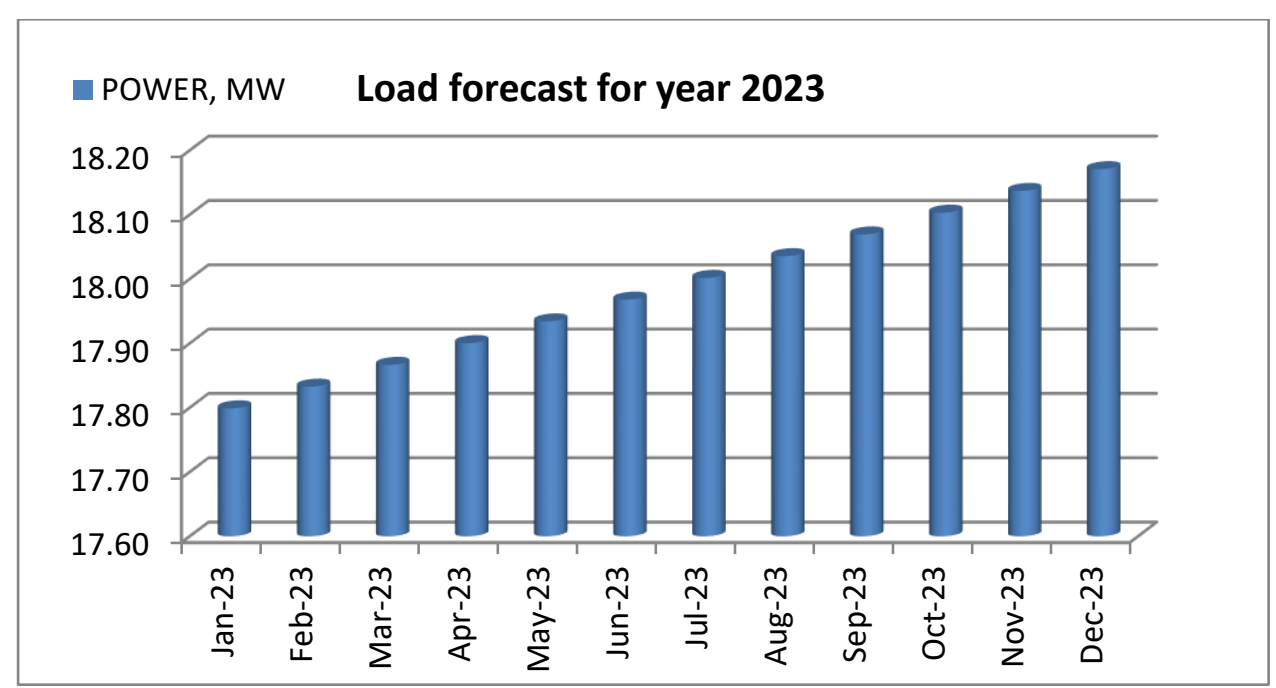

Figure 4.4: Bonny Island year 2023 load forecast 


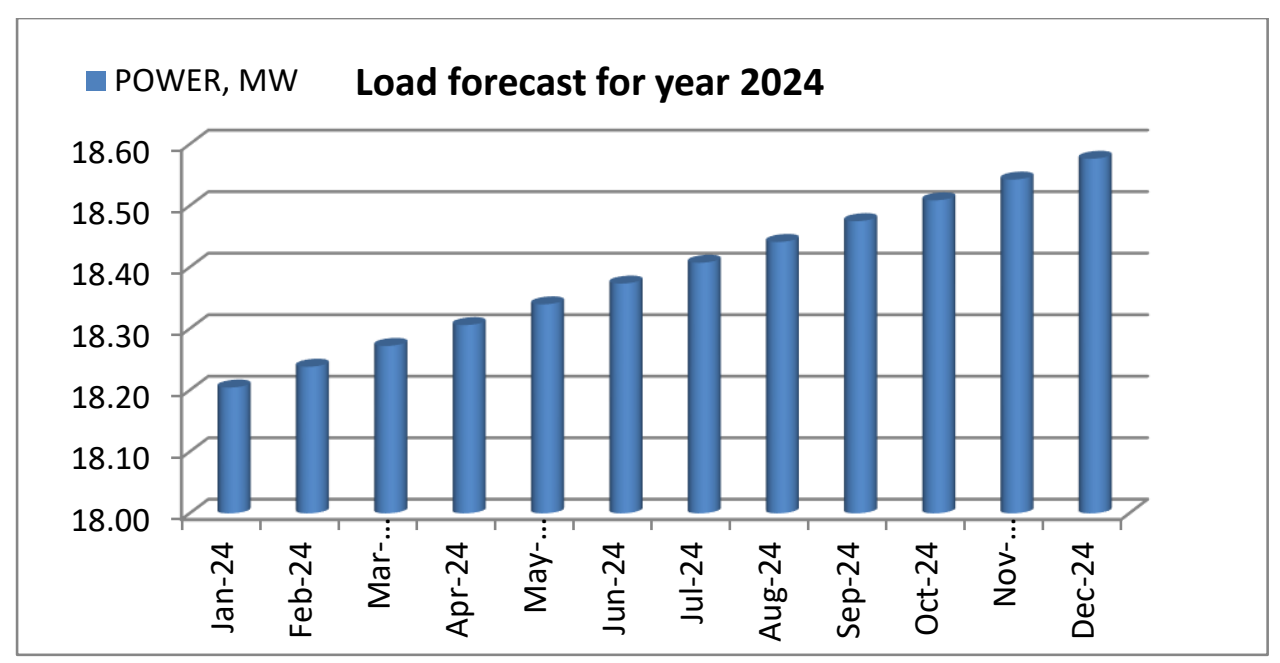

Figure 4.5: Bonny Island year 2024 load forecast

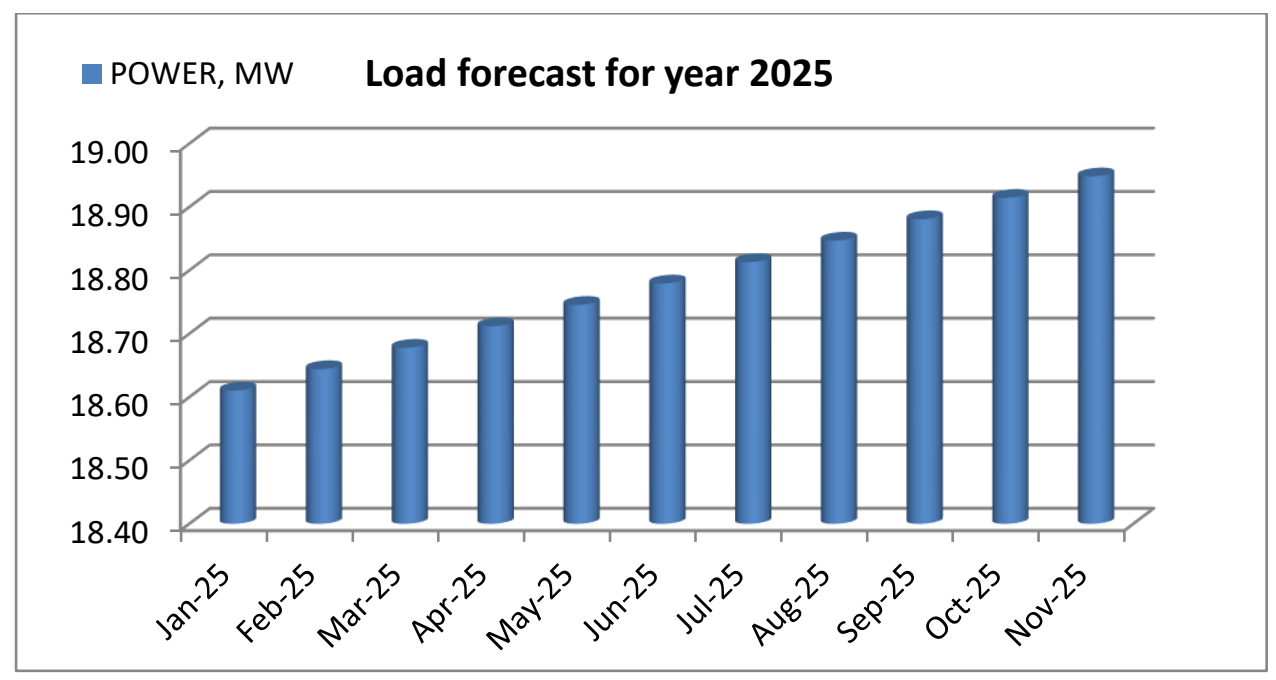

Figure 4.6: Bonny Island year 2025 load forecast

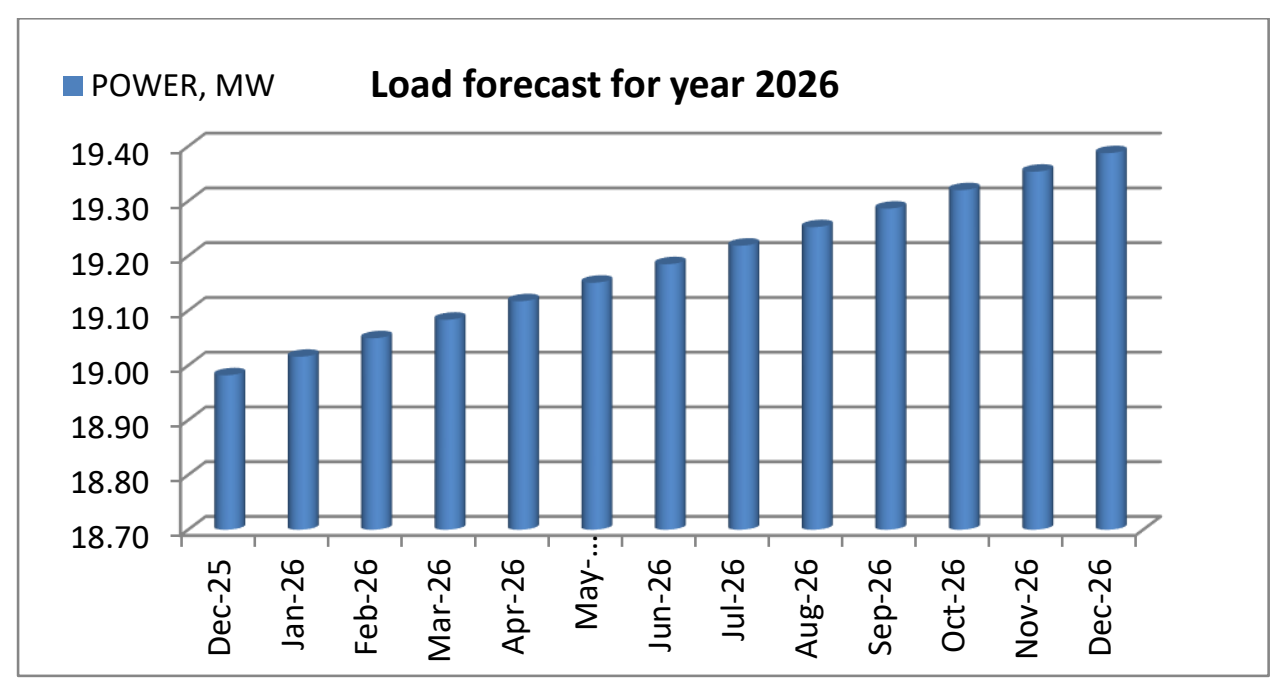

Figure 4.7: Bonny Island year 2026 load forecast 


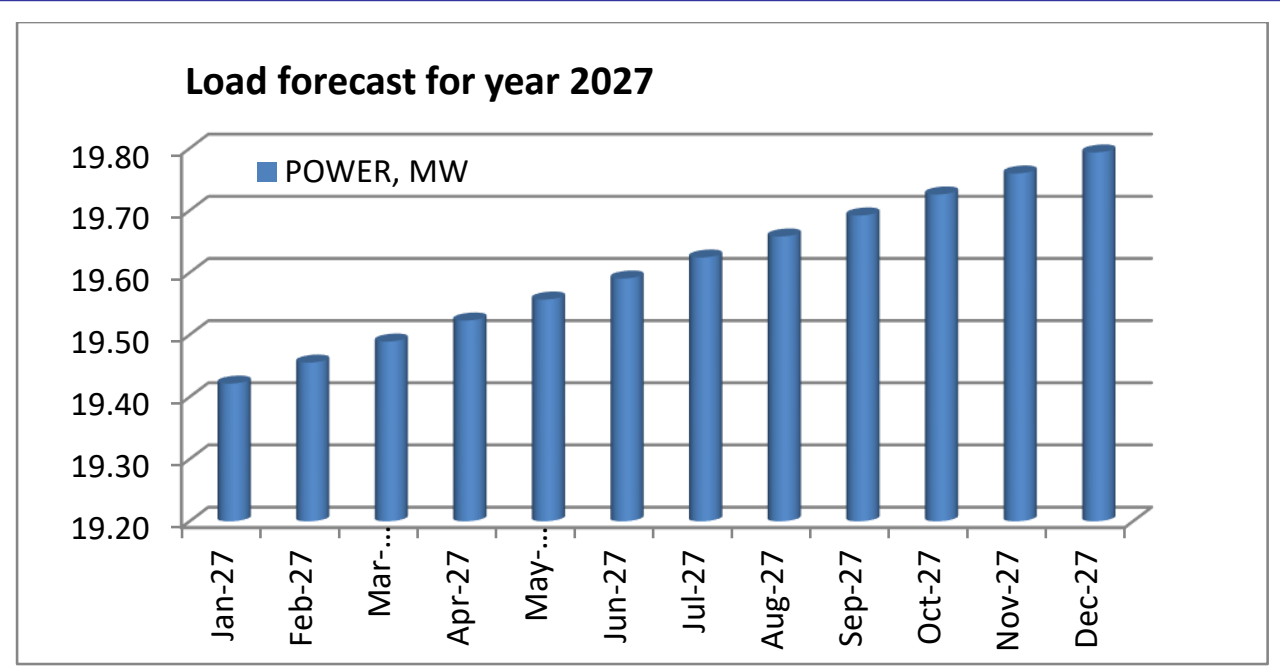

Figure 4.8: Bonny Island year 2027 load forecast

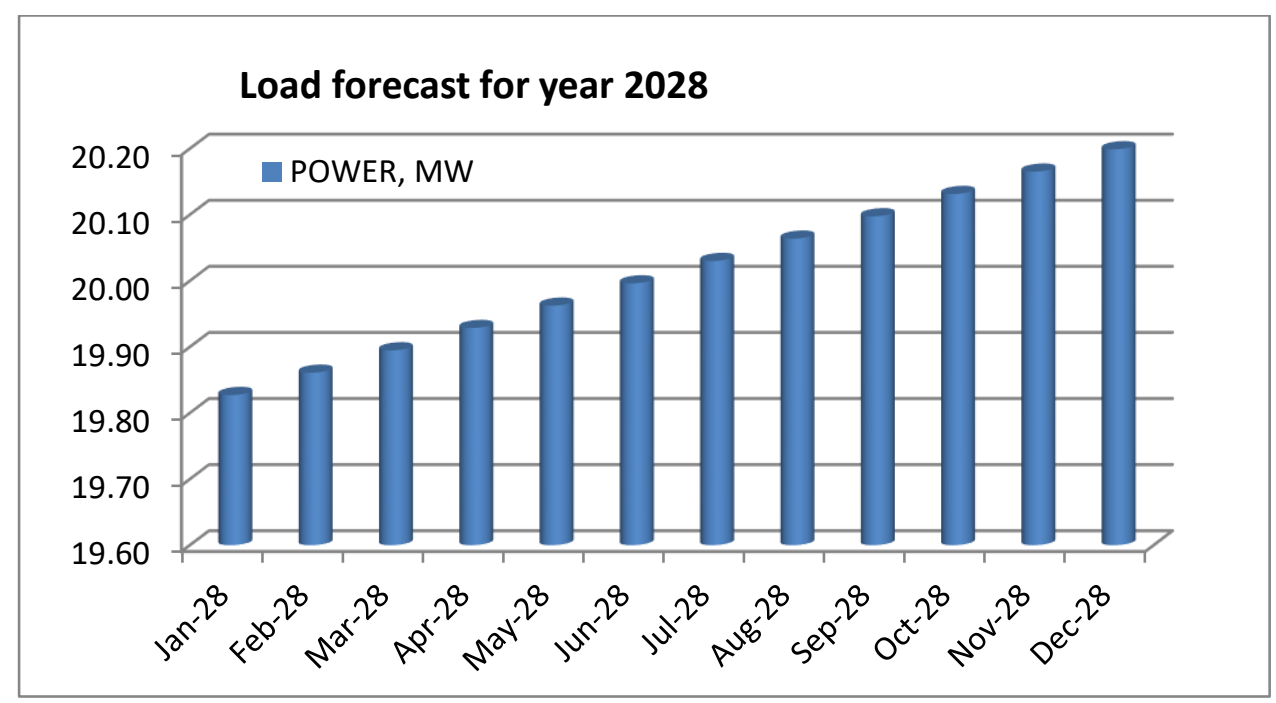

Figure 4.9: Bonny Island year 2028 load forecast

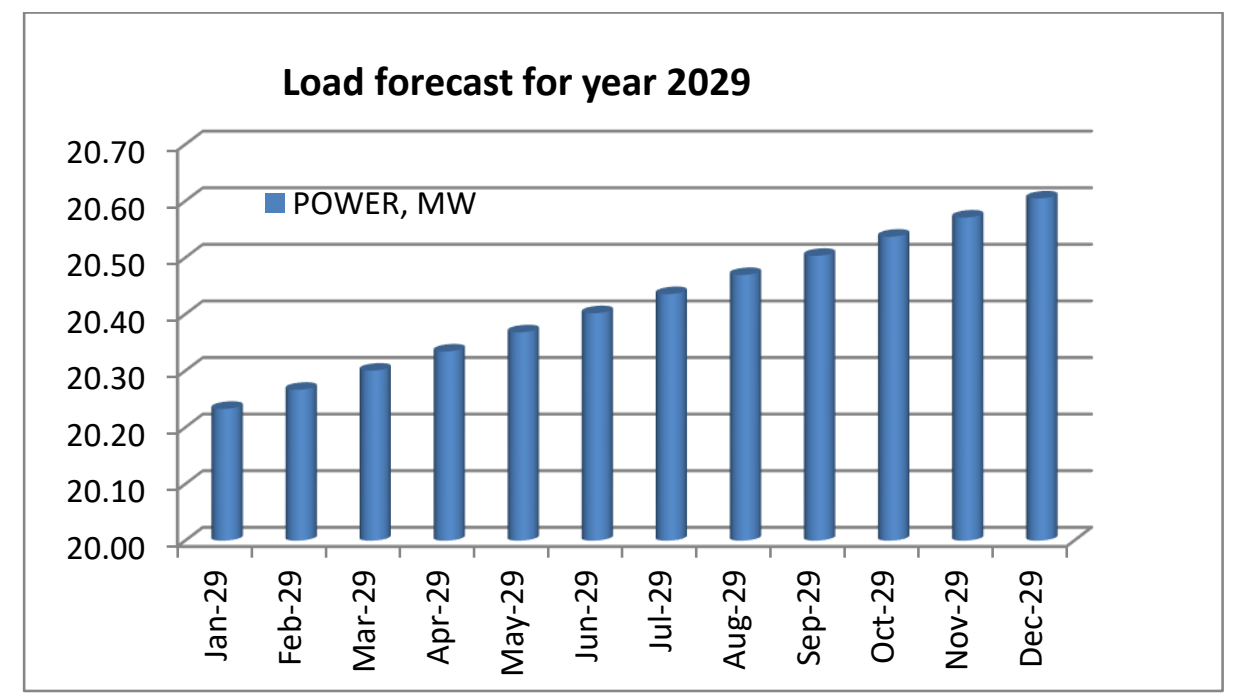

Figure 4.10: Bonny Island year 2029 load forecast 


\section{POWER, MW Load forecast for year $\mathbf{2 0 3 0}$}

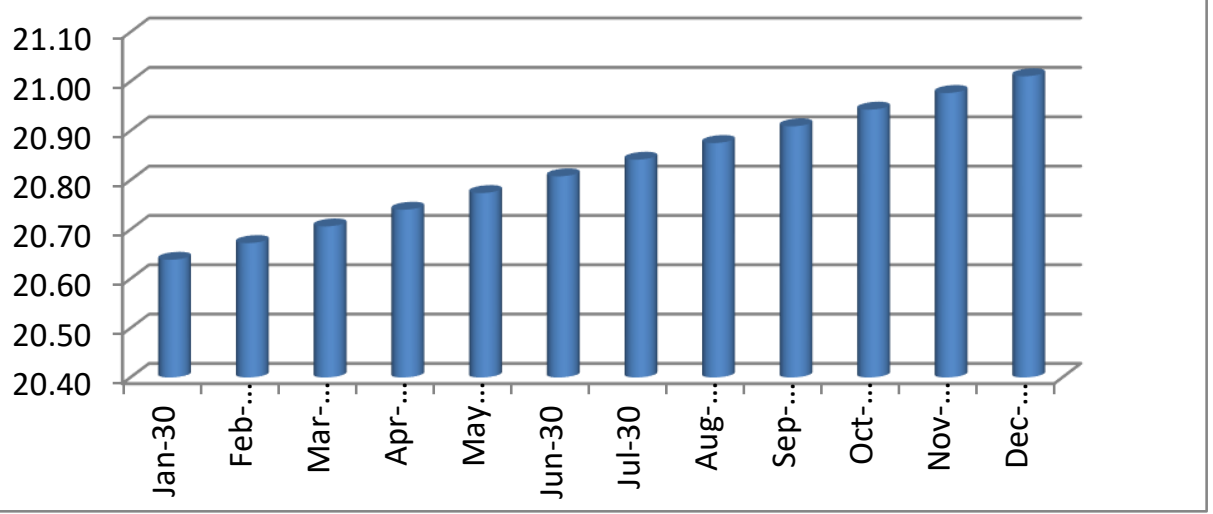

Figure 4.11: Bonny Island year 2030 load forecast

From Figure 4.1 to 4.11 above, it is expected that there will be steady load growth for Bonny Island from $16.6 \mathrm{MW}$ to over $21 \mathrm{MW}$ in next 10-years. By the end of 2027, the combined installed capacity by NLNG and SPDC would hit its limit of 20MW.

\section{CONCLUSION}

A long-term load forecast of Bonny Island is the focus of this paper. Regression analysis of sample load data (collected between January 2017 and September 201)9 has been detailed.

Results of the models used, reveal an increase in load consumption during the dry season and a reduction in load during the raining seasons. This means that power demand and supply can be at the minimum during this period, and major maintenance, upgrade operation on the power generation and distribution system can take place during this period.

Taking into account the various factors affecting load demand and forecasting, Bonny island may exceed it 20MW capacity currently supply by NLNG and SPDC earlier than 2027. As such both companies should review it power supply strategy to the Bonny communities and plan the upgrade of its power distribution network at the earliest possible time.

Further work on the use of artificial intelligence for this study should be explored to get more accurate load forecast.

\section{REFERNCES}

[1] Elakrmi F. \& Shikhah N.A. (2013): Electricity Load Forecasting - Science and Practices Pp. 1-2.

[2] Isaac A.S, et al, (2014): Medium-Term Load Forecasting Of Covenant University Using The Regression Analysis Methods Journal of Energy Technologies and Policy ISSN 2225-0573 Vol.4, No.4, Pp.10-11

[3] Opuenebo B. O. (2004): A Partnership Framework for Managing an Emerging Urban Region: The Bonny Experiment in Rivers State, Nigeria, $40^{\text {th }}$ ISoCaRP Congress Pp. 1-7.

[4] Panda S.K, et al. (2017): Applicability of End Use Method for Long Term Load Forecasting of Islands International Journal on Future Revolution in Computer Science \& Communication Engineering ISSN: 2454-4248 Volume: 3 Issue: 8 Pp.32

[5] Phuangpornpitak N. \& Prommee W. (2016): A Study of Load Demand Forecasting Models in Electric Power System Operation and Planning GMSARN International Journal 10. Pp.19-23
[6] Varlaan P.A.J (2018): Metocean Reference Document for NLNG Train-7 Nigeria; A shell Global Solutions International B.V. Report Pp. 3; 16-18

[7] Arokoyu S.B. \& Ogoro M. (2014): Vulnerability of Bonny Coastal Communities to Sea Level Changes Pp. 33-36

[8] Ede P.N, et al. ( 2011): Aspects of Air Quality Status of Bonny Island, Nigeria Attributed to an LNG Plant Pp. 892.

[9] Patrick D. et al ( 2014): Residential Power Load Forecasting Conference on Systems Engineering Research Pp. 3-4

[10] Jagadish H. P. (2010): Fuzzy Ideology based Long Term Load Forecasting; International Journal of Computer and Information Engineering Vol:4, No:4. Pp. 790-791

[11] Singh A.K. et al (2012): Load Forecasting Techniques and Methodologies: A Review Pp. 631-638.

[12] Olajuyin E. A. et al (2018): Long Term Load Forecasting Using Artificial Neural Network, American Journal of Engineering Research (AJER) Volume-7, Issue-11, Pp.14-15

[13] Vikas G. \& Seema P. (2017): An Overview of Different Types of Load Forecasting Methods and the Factors Affecting the Load Forecasting, International Journal for Research in Applied Science \& Engineering Technology, Volume 5 Issue IV, ISSN: 2321-9653 Pp. 730 